\title{
Current perspectives on the role of telemedicine in the management of Parkinson's disease
}

This article was published in the following Dove Press journal: Smart Homecare Technology and TeleHealth

\author{
Joel L Eisenberg ${ }^{1,2}$ \\ Jyhgong Gabriel Hou ${ }^{1,2}$ \\ Peter J Barbour ${ }^{1,2}$ \\ 'Department of Neurology, Lehigh \\ Valley Health Network, Allentown, PA, \\ USA; ${ }^{2}$ Morsani College of Medicine, \\ University of South Florida, Tampa, \\ FL, USA
}

\begin{abstract}
Parkinson's disease (PD) is a progressive neurological disorder that primarily affects older adults. The number of patients who receive specialty care continues to be limited, even though the benefits of seeing a movement disorder specialist for management of PD have been well established. Telemedicine has been suggested as a useful tool in addressing the problem of access to specialty care. As evidenced by the literature, it has been suggested that using telemedicine to treat PD is feasible and economically advantageous for both patients and providers. A high level of interest exists on both sides, and a high level of patient and provider satisfaction has been reported. The quality of care provided to patients with PD via telemedicine is comparable to inperson care based on objective measures. Additionally, telemedicine can increase access to care for certain patient populations. The current shortcomings of telemedicine that limit widespread use of the technology include technological barriers, limitations of the virtual exam, limited patient access to technology, weaknesses of current research, ongoing difficulties negotiating reimbursement for virtual visits, and licensing difficulties. We propose an ideal telemedicine system for PD set up as a remote clinic to ensure consistency across patient encounters. This clinic would have adequate support staff to conduct the physical exam, organize patient scheduling and discharge instructions, and coordinate ancillary services for patients including physical therapy, occupational therapy, psychological services, speech and language therapy, and social services. The future of telemedicine for the treatment of PD is promising, but broader research is needed to understand the challenges of patients living with PD. New portable technologies for monitoring symptoms and delivering treatment will continue to change the landscape, but it will still be some time before these technologies can be streamlined into virtual care without the need for in-person assessments and adjustments.
\end{abstract}

Keywords: movement disorders, video conferencing, access to care, neurology, nursing home, home healthcare

\section{Introduction}

Parkinson's disease (PD) is a progressive neurological disorder that can develop at any age, but primarily affects older adults. ${ }^{1}$ Presentation and speed of progression vary from patient to patient, but the disease is defined by its motor symptoms: resting tremors, bradykinesia, rigidity, and postural instability. ${ }^{2}$ Patients affected with PD may also develop difficulty swallowing and speaking. Autonomic dysfunction can result in bowel and bladder problems, postural hypotension, and sexual dysfunction. ${ }^{3}$ Other non-motor symptoms include sleep disturbances, cognitive decline, anxiety and depression. ${ }^{4,5}$ Individuals with this progressive illness experience better outcomes under the care of a neurologist. Neurologist-treated patients have fewer hospitalizations
Correspondence: Jyhgong Gabriel Hou Department of Neurology, Lehigh Valley Health Network, 1250 South Cedar Crest Boulevard, Suite 405 Allentown, PA 18103, USA

Tel + I 6104028420

Fax + I 6104021689

Email Jyh-Gong_G.Hou@Ivhn.org
Smart Homecare Technology and TeleHealth 2018:5 I-12

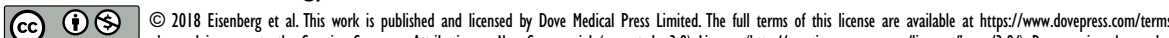
Dovepress f 1 in $\nabla$ http: //dxdoi.0rg/ 10.214715 HTT 
related to Parkinsonian symptoms, psychosis, urinary tract infections, and traumatic injury. ${ }^{6}$

The number of patients who receive specialty care continues to be limited, even though the benefits of seeing a movement disorder specialist for management of PD have been well established. ${ }^{6}$ Access to care remains a major barrier in rural areas where there are fewer movement disorder specialists. ${ }^{5}$ Access to movement disorder specialists is even worse in developing countries. ${ }^{7}$

Telemedicine, defined as the delivery of healthcare through real-time video conferencing between patient and provider, is particularly well-suited for evaluation of PD as assessment of PD is primarily observational. It may not be appropriate to make an initial diagnosis using remote evaluation, but it has been suggested that the use of telemedicine could be more cost effective and convenient than in-person follow-up visits for PD and other neurologic conditions. ${ }^{5,8-13}$

Other technologies that have proven useful for the management of PD include wearable monitors, accelerometers, and sensors, often adapted from a patient's smartphone and providing treatment teams with a clearer understanding of symptoms over time. ${ }^{14-41}$ Smart phone technologies hold great promise for the future management of PD, but current telemedicine for the management of $\mathrm{PD}$ is limited to the delivery of healthcare through synchronous, real-time video conferencing between patient and provider. The current shortcomings of telemedicine that limit widespread use of the technology include technological barriers, limitations of the virtual exam, limited patient access to technology, weaknesses of current research, ongoing difficulties negotiating reimbursement for virtual visits, and licensing difficulties.

The body of literature on this topic has indicated that using telemedicine to treat PD is feasible $e^{8,9,13,42-44}$ and economically advantageous ${ }^{5,8-13}$ for both patients and providers. A high level of interest exists on both sides and, in the trials that have been done, high levels of patient and provider satisfaction were reported..$^{9-13,42-45}$ Objective measures have shown that the quality of care provided to patients with PD via telemedicine is comparable to in-person care. $8,9,12,13,42,46,47$ Additionally, telemedicine has been shown to increase access to care for patients with PD living in nursing homes. ${ }^{13,42,47}$

Through this review, we will illustrate the advantages of telemedicine over traditional, in-person care once a definitive diagnosis has been made and a patient-provider relationship has been established through an in-person appointment. We conducted a thorough literature search and identified the earliest article to our knowledge (published in 1992) that specifically focused on the treatment of PD through video conferencing. For this review, 43 articles were thoroughly examined. Thirteen of these - with studies conducted between 2006 and 2017 - were included as the focus of this article on the basis of their relevance, quality, and scope. We will use our exploration of the advantages and disadvantages of these past and present models to propose what we believe to be an ideal system for telemedicine for Parkinson's disease. The future of the field will also be discussed.

\section{Advantages of telemedicine Feasibility}

Telemedicine feasibility has been measured as the percentage of telemedicine visits completed as scheduled. ${ }^{8,9,43,45}$ The main area of focus for most feasibility studies has been on the virtual visits replacing a typical, in-person, outpatient visit to a movement disorder specialist. These visits typically include gathering a thorough medical and neurological history, acquiring subjective information from established patients about their symptoms and daily functioning, and performing a physical assessment of neurological functioning. Patient progress is assessed, and a plan is determined between the neurologist, the patient, and the caregiver.

A partial randomized controlled trial (RCT) published in 2010 by Dorsey et $a 1,{ }^{42}$ sought to determine the feasibility of delivering virtual care from a movement disorder specialist at the University of Rochester to members of the community of New Hartford, NY (130 miles away). This study was the first in this area of study to be both randomized and controlled; it was also the first to include nursing home patients. Of the ten patients from the community, six were randomized to complete three virtual visits at the nursing home over 6 months $-100 \%$ of these visits were completed. All four of the nursing home patients were assigned to receive telemedicine care; $92 \%$ (11 of 12 ) of these visits took place. ${ }^{42}$

In 2013, Dorsey et $\mathrm{al}^{8}$ published a larger RCT comparing "virtual house calls" with typical in-person care. They found that a greater percentage of telemedicine visits were completed as scheduled than were in-person visits $(93 \%$ vs $91 \%$ ). Of the three missed in-person visits, one was due to a desire to minimize travel and another was due to a car accident on the way to a visit. This establishes the possibility that virtual visits may be more feasible than in-person visits in certain situations. ${ }^{8}$ A 2014 study by Venkataraman et al ${ }^{43}$ further demonstrated the feasibility of providing neurologic care directly in patients' homes by providing more than 50 remote consultations with few technical issues.

One of the largest and most comprehensive studies to date was conducted by Beck et $\mathrm{al}^{9}$ in 2017, using a trial 
design that had already been published by Dorsey et $\mathrm{a}^{48}$ the previous year. This RCT included 195 participants and lasted 1 year, comparing usual care by a neurologist to usual care supplemented by four in-home virtual visits. This study used intention-to-treat analysis and found that $98 \%$ of the intervention group completed at least one virtual visit. Overall, 91\% of 388 virtual visits were completed as scheduled. ${ }^{9}$

An aspect of feasibility that can be examined in this context is sustainability, or feasibility over time. Barbour et $\mathrm{al}^{13}$ demonstrated success in delivering telemedicine to patients living in a continuous care facility for 3 years. This study was published in 2016, and some of these original patients are still receiving care via telemedicine at the time of this publication (P. J. Barbour, oral communication, March 2018). The only other study with similar follow-up is Samii et $\mathrm{al}^{10}$ (2006); however, the video conferencing technology employed by their team was such that comprehensive motor assessments could not be completed for most visits. The studies looking at feasibility as a primary outcome are summarized in Table 1.

\section{Improved access to care and economic advantages}

Time requirements and cost of travel limit access to neurological care. In addition, patients affected with PD - because of their physical disabilities - may be unable to travel long distances to see a movement disorder specialist. It has been suggested that telemedicine may be more cost-effective than in-person care for patients with PD given their specific barriers to care.

In a study conducted by Samii et al, ${ }^{10}$ telemedicine was used for 100 follow-up visits for 34 patients with PD within the Veterans Health Administration. Estimated total savings amounted to 1,500 travel hours, 100,000 travel kilometers, and $\$ 37,000$ USD in travel and lodging costs, equating to average savings of approximately 44 travel hours, 2,941 travel kilometers, and $\$ 1,088$ per patient. These savings are especially significant for the veteran population, as these patients tend to have lower incomes than the general population. ${ }^{50}$

Dorsey et $\mathrm{al}^{8}$ in 2013 found that patients saved an average of 100 miles of travel $(161 \mathrm{~km})$ and 3 hours of time per visit by receiving telemedicine visits at home. Whereas the time spent with a physician did not differ significantly between the telemedicine group and the group that received in-person care, the time spent without a physician in the telemedicine group was much lower than in the group that received inperson care (18 minutes vs 207 minutes; $P<0.001) .{ }^{8}$

Pretzer-Aboff and Prettyman ${ }^{5}$ described a unique, multidisciplinary clinic design in which a movement disorder specialist and a clinical psychologist were able to teleconference into a clinic that employed nurse practitioners, researchers, physical and speech therapists, exercise physiologists, nutritionists, and graduate students providing in-person care. The authors estimated the average reduction in travel time/ distance to be 1.5 hours $/ 80$ miles $(123 \mathrm{~km})$ each way for each of their 36 patients. ${ }^{5}$

Table I Summary of studies investigating feasibility as a primary outcome

\begin{tabular}{|c|c|c|c|}
\hline $\begin{array}{l}\text { Author (year) } \\
\text { Sample size (n) } \\
\text { Duration (d) }\end{array}$ & Setting & Intervention & Feasibility \\
\hline $\begin{array}{l}\text { Dorsey et } \mathrm{al}^{42} \\
\mathrm{n}=\mid 4 \\
\mathrm{~d}=6 \text { months }\end{array}$ & Nursing home & $\begin{array}{l}\text { Video visits in a nursing home were } \\
\text { compared to usual care }\end{array}$ & $\begin{array}{l}\text { Patients from local community and nursing } \\
\text { home completed } 100 \% \text { and } 92 \% \text { of virtual visits, } \\
\text { respectively }\end{array}$ \\
\hline $\begin{array}{l}\text { Dorsey et } \mathrm{al}^{8} \\
\mathrm{n}=20 \\
\mathrm{~d}=7 \text { months }\end{array}$ & Patient's home & $\begin{array}{l}\text { In-home telemedicine visits were compared } \\
\text { to in-person care }\end{array}$ & $\begin{array}{l}\text { A greater percentage of telemedicine visits } \\
\text { were completed as scheduled than in-person } \\
\text { visits ( } 93 \% \text { vs } 91 \%)\end{array}$ \\
\hline $\begin{array}{l}\text { Venkataraman et } \mathrm{al}^{43} \\
\mathrm{n}=55 \\
\mathrm{~d}=\text { single visit }\end{array}$ & $\begin{array}{l}\text { Patient's home } \\
\text { and local facilities }\end{array}$ & Patients were offered a single video visit & All visits were completed as scheduled \\
\hline $\begin{array}{l}\text { Dorsey et } \mathrm{al}^{44} \\
\mathrm{n}=204 \\
\mathrm{~d}=\text { single visit }\end{array}$ & Patient's home & $\begin{array}{l}\text { Video conferencing connected participants } \\
\text { with specialists to determine feasibility of } \\
\text { virtual research visits }\end{array}$ & $\begin{array}{l}81 \% \text { of consenting participants completed all } \\
\text { visits }\end{array}$ \\
\hline $\begin{array}{l}\text { Barbour et } \mathrm{al}^{13} \\
\mathrm{n}=16 \\
\mathrm{~d}=3 \text { years }\end{array}$ & Nursing home & $\begin{array}{l}\text { Patients living in a continuous care facility } \\
\text { were provided with long-term care via } \\
\text { telemedicine }\end{array}$ & $\begin{array}{l}\text { Using telemedicine at a long-term care facility } \\
\text { was found to be sustainable }\end{array}$ \\
\hline $\begin{array}{l}\text { Beck et al } \\
n=195 \\
d=I \text { year }\end{array}$ & Patient's home & $\begin{array}{l}\text { Usual care by neurologist was compared to } \\
\text { usual care supplemented by four in-home } \\
\text { virtual visits }\end{array}$ & $\begin{array}{l}91 \% \text { of } 388 \text { virtual visits were completed as } \\
\text { scheduled }\end{array}$ \\
\hline
\end{tabular}


A survey administered to both users and non-users of telemedicine found that patients utilizing telemedicine saved an average of $\$ 200$ and 209 minutes in travel time, with a reduction of $160 \mathrm{~km}$ in distance traveled per visit. ${ }^{11} \mathrm{An}$ RCT centered on patient satisfaction had two arms, one comparing patients receiving telemedicine at home with typical care, and the second comparing patients receiving telemedicine at a satellite clinic closer to their homes with typical inperson care; patient satisfaction was significantly higher in both telemedicine groups for survey items related to travel distance, travel time, and general convenience. ${ }^{12}$

Reductions in cost are also possible for patients living in a continuous care facility. Under normal circumstances, patients would have to be transported by ambulance, an attendant, or a family member to their appointments. Even without factoring in the cost of hiring a medical aide to accompany patients, the cost of a telemedicine visit for these patients was found to be less than the facility's average cost for transporting patients. ${ }^{13}$

The RCT conducted by Beck et al ${ }^{9}$ in 2017 strengthened the case for telemedicine as a way to reduce travel time and distance for the patients, who saved an average of 88 minutes and 38 miles per virtual visit. Table 2 summarizes articles in which cost reduction was identified as a primary outcome of telemedicine.

\section{Patient interest and satisfaction}

\section{Patients show interest in telemedicine because of its} convenience relative to typical office visits.

A survey distributed in 2015 by Qiang and Marras ${ }^{11}$ to patients with PD (both non-users and users of telemedicine) found that more than half of the non-users were interested in telemedicine, but the option had not been offered to them. Additionally, $85 \%$ of patients currently receiving telemedicine in this study wanted to continue with this treatment modality. ${ }^{11}$

Patients who participate in telemedicine for the treatment of PD report a high level of satisfaction with the care they receive. In a trial conducted in 2010 by Dorsey et al, ${ }^{42} 13$ of 14 patients opted to receive specialty care via telemedicine in the future. Venkataraman et $\mathrm{al}^{43}$ reported in 2014 that $100 \%$ of the 33 patients who completed an after-visit survey were

Table 2 Summary of studies investigating cost reduction as a primary outcome

\begin{tabular}{|c|c|c|c|}
\hline $\begin{array}{l}\text { Author (year) } \\
\text { sample size (n) } \\
\text { Duration (d) }\end{array}$ & Setting & Intervention & Cost reduction \\
\hline $\begin{array}{l}\text { Samii et } \text { al }^{10} \\
\mathrm{n}=34 \\
\mathrm{~d}=3 \text { years }\end{array}$ & $\begin{array}{l}\text { Nursing homes, } \\
\text { satellite clinics }\end{array}$ & $\begin{array}{l}\text { A total of } 100 \text { telemedicine follow-up visits } \\
\text { were performed }\end{array}$ & $\begin{array}{l}\text { Total estimated patient savings of } 1,500 \\
\text { travel hours, } 100,000 \text { travel } \mathrm{km} \text {, and } \$ 37,000 \\
\text { in travel and lodging costs }\end{array}$ \\
\hline $\begin{array}{l}\text { Dorsey et } \mathrm{al}^{8} \\
\mathrm{n}=20 \\
\mathrm{~d}=7 \text { months }\end{array}$ & Patient's home & $\begin{array}{l}\text { In-home telemedicine visits were compared } \\
\text { to in-person care }\end{array}$ & $\begin{array}{l}\text { Patients saved an average of } 100 \text { travel miles } \\
\text { and } 3 \text { hours per visit, spending less time with } \\
\text { a physician than when receiving in-person } \\
\text { care ( } 18 \text { minutes vs } 207 \text { minutes) }\end{array}$ \\
\hline $\begin{array}{l}\text { Pretzer-Aboff and Prettyman } \\
\mathrm{n}=36 \\
\mathrm{~d}=6 \text { months }\end{array}$ & $\begin{array}{l}\text { Multi-disciplinary } \\
\text { PD clinic }\end{array}$ & $\begin{array}{l}\text { A multi-disciplinary PD clinic was } \\
\text { developed, in which a movement disorder } \\
\text { specialist and a clinical psychologist could } \\
\text { see patients via telemedicine }\end{array}$ & $\begin{array}{l}\text { Each patient reduced travel time/distance by } \\
\text { an estimated } 1.5 \text { hours, } 80 \text { miles, each way }\end{array}$ \\
\hline $\begin{array}{l}\text { Qiang and Marras" } \\
\mathrm{n}=137 \\
\mathrm{~d}=\mathrm{N} / \mathrm{A}\end{array}$ & N/A & $\begin{array}{l}\text { A survey was distributed to } 34 \text { users of } \\
\text { telemedicine and } 103 \text { non-users }\end{array}$ & $\begin{array}{l}\text { Patients saved an average of } \$ 200 \text { and } 209 \\
\text { minutes in travel time with a reduction of } \\
160 \mathrm{~km} \text { in distance traveled per visit }\end{array}$ \\
\hline $\begin{array}{l}\text { Wilkinson et } \text { al }^{12} \\
\mathrm{n}=86 \\
\mathrm{~d}=\mathrm{I} \text { year }\end{array}$ & $\begin{array}{l}\text { Patient's home, } \\
\text { satellite clinic }\end{array}$ & $\begin{array}{l}\text { Survey completed by patients receiving } \\
\text { telemedicine care at home and in a satellite } \\
\text { clinic was compared with patients receiving } \\
\text { in-person care }\end{array}$ & $\begin{array}{l}\text { Patient satisfaction was higher in both } \\
\text { telemedicine groups for survey items related } \\
\text { to travel distance, travel time, and general } \\
\text { convenience }\end{array}$ \\
\hline $\begin{array}{l}\text { Barbour et } \mathrm{al}^{13} \\
n=16 \\
d=3 \text { years }\end{array}$ & Nursing home & $\begin{array}{l}\text { Patients living in a continuous care facility } \\
\text { were provided with long-term care via } \\
\text { telemedicine }\end{array}$ & $\begin{array}{l}\text { The cost of a telemedicine visit }(\$ \mid I 7.30) \\
\text { was found to be less than the facility's } \\
\text { average cost for transporting a patient to the } \\
\text { neurologist's office }\end{array}$ \\
\hline $\begin{array}{l}\text { Beck et al } \\
n=195 \\
d=1 \text { year }\end{array}$ & Patient's home & $\begin{array}{l}\text { Usual care by neurologist was compared to } \\
\text { usual care supplemented by four in-home } \\
\text { virtual visits }\end{array}$ & $\begin{array}{l}\text { Patients saved an average of } 88 \text { minutes and } \\
38 \text { miles per virtual visit }\end{array}$ \\
\hline
\end{tabular}

Abbreviations: N/A, not applicable; PD, Parkinson's disease. 
either "likely" or "very likely" to recommend telemedicine to a friend. While some concerns about technological difficulties have been raised, nearly $90 \%$ of users in one survey reported being "satisfied" or "very satisfied" with the technological aspects of telemedicine. ${ }^{11}$

The available data indicate that patient satisfaction has increased over time, suggesting that the difficulties encountered in earlier studies are becoming less problematic as the technology improves. A large dual-arm RCT published in 2016 found high levels of patient satisfaction overall but discovered that patients receiving care via telemedicine at home and at a satellite clinic were more satisfied in areas related to convenience and accessibility compared to the control arms. ${ }^{12}$ Barbour et $\mathrm{al}^{13}$ confirmed in 2016 that patient satisfaction with telemedicine was high. The most recent $\mathrm{RCT}$ published to date reported the highest patient satisfaction yet: $97 \%$ of patients with PD were either "satisfied" or "very satisfied" with their telemedicine experience, preferring virtual visits to in-person care on all aspects measured. ${ }^{9}$
Providers who have participated in telemedicine visits also rate their experiences highly. In a study that used telemedicine for 100 follow-up visits with duration of more than 3 years, providers chose "strongly agree" or "agree" for all survey items indicating that their experience with the encounter was positive in 99 out of 100 visits. ${ }^{10}$ A more recent study reported that $86 \%$ of physicians were satisfied or very satisfied with virtual visits. ${ }^{9}$ Studies that examined patient and provider satisfaction to telemedicine care are summarized in Table 3.

\section{Validity, reliability, and quality of care}

A crucial component of the typical visit for a patient with PD is the physical assessment. This provides the physician with a thorough understanding of a patient's motor functioning and behavior, as well as an individual's ability to perform activities of daily living. The Unified Parkinson's Disease Rating Scale (UPDRS) was developed to allow clinicians to assign a severity score to patients as a way to capture their disease severity and track their progress over time (a higher score

Table 3 Summary of studies investigating satisfaction as a primary outcome

\begin{tabular}{|c|c|c|c|}
\hline $\begin{array}{l}\text { Author (year) } \\
\text { sample size (n) } \\
\text { Duration (d) }\end{array}$ & Setting & Intervention & Satisfaction \\
\hline $\begin{array}{l}\text { Samii et } \text { al }^{10} \\
\mathrm{n}=34 \\
\mathrm{~d}=3 \text { years }\end{array}$ & $\begin{array}{l}\text { Nursing } \\
\text { homes, satellite } \\
\text { clinics }\end{array}$ & $\begin{array}{l}\text { A total of } 100 \text { telemedicine follow-up visits } \\
\text { were performed }\end{array}$ & $\begin{array}{l}\text { Providers agreed or strongly agreed with statements } \\
\text { regarding their satisfaction with telemedicine for all } \\
\text { questions in } 99 \text { of } 100 \text { visits }\end{array}$ \\
\hline $\begin{array}{l}\text { Dorsey et } \mathrm{al}^{42} \\
\mathrm{n}=13 \\
\mathrm{~d}=6 \text { months }\end{array}$ & Nursing home & $\begin{array}{l}\text { Video visits in a nursing home were } \\
\text { compared to usual care }\end{array}$ & $\begin{array}{l}\text { I3 of } 14 \text { patients opted to receive specialty care via } \\
\text { telemedicine in the future; changes in patient satisfaction } \\
\text { were not statistically significant }\end{array}$ \\
\hline $\begin{array}{l}\text { Shprecher et } \mathrm{a}^{45} \\
\mathrm{n}=1 \mathrm{I} / 3 \\
\mathrm{~d}=\mathrm{N} / \mathrm{A}\end{array}$ & N/A & $\begin{array}{l}\text { A survey was distributed to patients being } \\
\text { treated at a University PD clinic about a } \\
\text { hypothetical research study }\end{array}$ & $\begin{array}{l}\text { Patients were more willing to participate in clinical trials } \\
\text { if some or most of the visits occurred via telemedicine } \\
\text { at a local clinic }\end{array}$ \\
\hline $\begin{array}{l}\text { Venkataraman et } \mathrm{al}^{43} \\
\mathrm{n}=55 \\
\mathrm{~d}=\text { single visit }\end{array}$ & $\begin{array}{l}\text { Patient's home, } \\
\text { satellite clinic }\end{array}$ & Patients were offered a single video visit & $\begin{array}{l}100 \% \text { of patients that completed survey were likely or } \\
\text { very likely to recommend telemedicine to a friend }\end{array}$ \\
\hline $\begin{array}{l}\text { Dorsey et } \text { al }^{44} \\
\mathrm{n}=204 \\
\mathrm{~d}=\text { single visit }\end{array}$ & Patient's home & $\begin{array}{l}\text { Video conferencing connected participants } \\
\text { with specialists to determine feasibility of } \\
\text { virtual research visits }\end{array}$ & $\begin{array}{l}\text { Overall satisfaction (satisfied or very satisfied) was } 79 \% \\
\text { among neurologists and } 93 \% \text { among participants }\end{array}$ \\
\hline $\begin{array}{l}\text { Qiang and Marras" } \\
\mathrm{n}=137 \\
\mathrm{~d}=\mathrm{N} / \mathrm{A}\end{array}$ & $N / A$ & $\begin{array}{l}\text { A survey was distributed to } 34 \text { users of } \\
\text { telemedicine and } 103 \text { non-users }\end{array}$ & $\begin{array}{l}53 \% \text { of non-users were interested in using telemedicine; } \\
\text { nearly } 90 \% \text { of users were highly satisfied or satisfied } \\
\text { with technical aspects of telemedicine }\end{array}$ \\
\hline $\begin{array}{l}\text { Wilkinson et } \mathrm{al}^{12} \\
\mathrm{n}=86 \\
\mathrm{~d}=\mathrm{I} \text { year }\end{array}$ & $\begin{array}{l}\text { Patient's home, } \\
\text { satellite clinic }\end{array}$ & $\begin{array}{l}\text { A survey completed by patients receiving } \\
\text { telemedicine care at home and in a satellite } \\
\text { clinic was compared to patients receiving } \\
\text { in-person care }\end{array}$ & $\begin{array}{l}\text { Patients receiving telemedicine were more satisfied in } \\
\text { areas related to convenience and accessibility }\end{array}$ \\
\hline $\begin{array}{l}\text { Barbour et } \mathrm{al}^{13} \\
\mathrm{n}=16 \\
d=3 \text { years }\end{array}$ & Nursing home & $\begin{array}{l}\text { Patients living in a continuous care facility } \\
\text { were provided with long-term care via } \\
\text { telemedicine }\end{array}$ & $\begin{array}{l}\text { All patients chose telemedicine when given the choice } \\
\text { of being followed in the office or via telemedicine }\end{array}$ \\
\hline $\begin{array}{l}\text { Beck et al9 } \\
n=195 \\
d=I \text { year }\end{array}$ & Patient's home & $\begin{array}{l}\text { Usual care by neurologist was compared to } \\
\text { usual care supplemented by four in-home } \\
\text { virtual visits }\end{array}$ & $\begin{array}{l}97 \% \text { of patients and } 86 \% \text { of physicians were either } \\
\text { satisfied or very satisfied with their telemedicine } \\
\text { experience }\end{array}$ \\
\hline
\end{tabular}

Abbreviations: N/A, not applicable; PD, Parkinson's disease. 
correlates to more disability). This scale has been widely utilized and has been shown to be valid and reliable. ${ }^{51}$ The Hoehn and Yahr Staging scale and the Schwab and England Activities of Daily Living Scale have also been used. Hoehn and Yahr scoring focuses primarily on postural instability as a measure of disease severity, whereas the Schwab and England scale assigns a percentage to a patient's ability to live independently. ${ }^{52}$ The Mini-Mental State Exam (MMSE) and the Montreal Cognitive Assessment (MoCA) have been shown to be effective in monitoring the cognitive decline in patients with PD. ${ }^{49,53}$

In some studies, nurses familiar with PD attended the telemedicine visits with patients to test for rigidity and postural instability. ${ }^{10,13,42,54}$ The need for specialized nursing staff can be more easily accommodated in nursing homes and continuous care facilities but can be costly and impractical for patients receiving telemedicine at home. In an effort to simplify virtual assessment, a modified version of the UPDRS (mUPDRS) was developed to eliminate the need for hands-on assessment. This modified version removed two components of the exam: a hands-on assessment of rigidity and the retropulsion pull test, in which a provider pulls a patient backward to assess postural instability. The mUPDRS is a reliable and valid measure of motor functioning and may be used to conduct remote assessments of patients in their homes without the need for trained nursing staff. ${ }^{55}$

It is interesting to explore whether patients with PD treated with telemedicine can be shown to make clinical improvements comparable to their counterparts receiving in-person care. In 2009, Biglan et $\mathrm{al}^{47}$ presented a promising case report in which a 77-year-old patient with $P D$ received care via telemedicine for 8 months. The patient improved his MMSE score (from 21 to 30; less cognitive disability), experienced less dyskinesia, and had an improved ability to feed himself. The following year, Dorsey et $\mathrm{al}^{42}$ showed further improvements: patients randomized to telemedicine improved UPDRS motor score by an average of 6.5 points, whereas patients receiving usual care worsened by an average of 0.3 points. A significant increase in quality of life, based on responses to the Parkinson's Disease Questionnaire 39 (PDQ39), was noted for patients in the telemedicine group, whereas the usual care group had a decrease in quality of life. ${ }^{42}$

Marzinzik et $\mathrm{al}^{46}$ explored the option of having patients upload videos of their motor functioning multiple times per day over 30 days to be viewed remotely by the treatment team. While this method of assessment is different from the synchronous video conferencing discussed to this point, it is still considered telemedicine because it is remote, virtual, video-based care. Improvements in these patients' UPDRS scores, based on drug adjustments made without seeing patients in person, were noted - from an average of 31 points at enrollment to 24 points at program end. More recent studies have found that improvement in UPDRS scores do not differ between telemedicine and control groups; we can reasonably assume that treatment outcomes for telemedicine, based on improvement in motor functioning, are objectively as good as they are for in-person care..$^{8,9,12,13}$ Studies that investigated quality in telemedicine care are summarized in Table 4.

\section{Limitations of telemedicine Weaknesses of current research}

The studies reviewed herein have had considerable limitations. Many of them lacked statistical power due to small sample size. ${ }^{8,12,42}$ In addition, the sample populations studied to date are not representative of the population living with PD. Nearly every study conducted has used a very selective subset of patients with PD - generally well-educated white men who are familiar with the internet - many of whom were already receiving specialist care. ${ }^{8,9,11,12,43,44}$ This disparity is especially troublesome, as research has demonstrated that African-Americans with PD are four times less likely than Whites to receive any form of care. ${ }^{56}$ Specific demographic data can be found in Table 5 .

Blinding, to reduce bias, is an important consideration in the design of an RCT. While blinding is difficult to achieve in this context (ie, concealing which patients received telemedicine care), lack of blinding could bias assessment of patient UPDRS scores. ${ }^{8,42}$

It is difficult to assess whether telemedicine is costeffective in a complex healthcare system. Most of the studies identified as focused on the economic advantages of telemedicine primarily investigated savings to the patients in the form of travel time, distance, and lodging costs. ${ }^{5,8-12}$ To our knowledge, only one study attempted to evaluate cost to the facility; however, this research team had difficulty reaching a sufficient cost reduction determination due to the number of variables that must be considered. ${ }^{13}$ It has yet to be adequately demonstrated that telemedicine is cost-effective for both patients, providers, and healthcare systems.

Many studies have reported high levels of patient satisfaction with telemedicine, ${ }^{9-13,42-45}$ but few of the satisfaction surveys used were standardized measures, making them subject to bias. Only two of the studies identified as measuring satisfaction used validated survey instruments, and they differed in the instruments they chose. ${ }^{12,42}$

The long-term outcomes of telemedicine remain unclear, as only two studies to our knowledge have followed patients 
Table 4 Summary of studies investigating quality as a primary outcome

\begin{tabular}{|c|c|c|c|}
\hline $\begin{array}{l}\text { Author (year) } \\
\text { sample size (n) } \\
\text { Duration (d) }\end{array}$ & Setting & Intervention & Telemedicine results \\
\hline $\begin{array}{l}\text { Biglan et } \mathrm{a}^{47} \\
\mathrm{n}=\mathrm{I} \\
\mathrm{d}=8 \text { months }\end{array}$ & Nursing home & $\begin{array}{l}\text { Nursing home resident received six telemedicine } \\
\text { visits }\end{array}$ & $\begin{array}{l}\text { Patient reported less dyskinesia, was better able } \\
\text { to feed himself, and MMSE improved from } 21 / 30 \\
\text { to } 30 / 30^{\mathrm{a}}\end{array}$ \\
\hline $\begin{array}{l}\text { Dorsey et } \mathrm{al}^{42} \\
\mathrm{n}=14 \\
\mathrm{~d}=6 \text { months }\end{array}$ & Nursing home & $\begin{array}{l}\text { Video visits in a nursing home were compared to } \\
\text { usual care }\end{array}$ & $\begin{array}{l}\text { On average, telemedicine patients improved } \\
\text { UPDRS score by } 6.5 \text { points, and control group } \\
\text { worsened by } 0.3 \text { points }\end{array}$ \\
\hline $\begin{array}{l}\text { Marzinzik et a }{ }^{46} \\
n=78 \\
d=I \text { month }\end{array}$ & Patient's home & $\begin{array}{l}\text { Patients sent video recordings of motor } \\
\text { functioning to treatment team, serving as the } \\
\text { basis for therapeutic decisions }\end{array}$ & $\begin{array}{l}\text { Average UPDRS score decreased from } 3 \mathrm{I} \text { points } \\
\text { at enrollment to } 24 \text { points at } 3 \text {-month follow-up } \\
\text { (patients had less impairment) }\end{array}$ \\
\hline $\begin{array}{l}\text { Dorsey et } \mathrm{al}^{8} \\
\mathrm{n}=20 \\
d=7 \text { months }\end{array}$ & Patient's home & $\begin{array}{l}\text { Compared in-home telemedicine visits to in- } \\
\text { person care }\end{array}$ & $\begin{array}{l}\text { Changes in mUPDRS score and PDQ-39c did not } \\
\text { differ significantly between telemedicine and in- } \\
\text { person care groups }\end{array}$ \\
\hline $\begin{array}{l}\text { Wilkinson et a }\left.\right|^{12} \\
n=86 \\
d=I \text { year }\end{array}$ & $\begin{array}{l}\text { Patient's home, } \\
\text { satellite clinic }\end{array}$ & $\begin{array}{l}\text { Survey completed by patients receiving } \\
\text { telemedicine care at home and in a satellite clinic } \\
\text { compared with patients receiving in-person care }\end{array}$ & $\begin{array}{l}\text { No significant differences in GDS, UPDRS, or } \\
\text { PDQ- } 8^{d} \text { scores were found between telemedicine } \\
\text { and in-person care groups }\end{array}$ \\
\hline $\begin{array}{l}\text { Barbour et } \text { al }^{13} \\
n=16 \\
d=3 \text { years }\end{array}$ & Nursing home & $\begin{array}{l}\text { Patients living in a continuous care facility were } \\
\text { provided with long-term care via telemedicine }\end{array}$ & $\begin{array}{l}\text { Study showed no clear effect on outcome as } \\
\text { measured by the UPDRS }\end{array}$ \\
\hline $\begin{array}{l}\text { Beck et al } \\
\mathrm{n}=\mid \mathrm{I} 95 \\
\mathrm{~d}=\mathrm{I} \text { year }\end{array}$ & Patient's home & $\begin{array}{l}\text { Compared usual care by neurologist to usual } \\
\text { care supplemented by four in-home virtual visits }\end{array}$ & $\begin{array}{l}\text { Change in clinical outcomes did not significantly } \\
\text { differ between the telemedicine group and the in- } \\
\text { person care group }\end{array}$ \\
\hline
\end{tabular}



Abbreviations: GDS, Geriatric Depression Scale; MMSE, Mini-Mental Status Examination; mUPDRS, Modified Unified Parkinson's Disease Rating Scale; PDQ, Parkinson's Disease Questionnaire; UPDRS, Unified Parkinson's Disease Rating Scale.

Table 5 Baseline characteristics of study participants ${ }^{\mathrm{a}}$

\begin{tabular}{lll}
\hline Characteristics of patients & $\begin{array}{l}\text { \# of } \\
\text { patients } \\
\text { satisfying } \\
\text { criteria/n }\end{array}$ & $\begin{array}{l}\text { Percentage } \\
\text { (\%) }\end{array}$ \\
\hline Gender, men, & \\
\hline Race, White, $912,42,43,44$ & $401 / 653$ & $61.4 \%$ \\
Regularly uses the internet at home & $475 / 502$ & $94.6 \%$ \\
Education, bachelor's degree or higher,42,44 & $351 / 361$ & $97.2 \%$ \\
Established patient with a PD specialist ${ }^{9,12,44}$ & $349 / 375$ & $74.4 \%$ \\
\hline
\end{tabular}

Notes: aDemographic information that was ambiguous or non-specific was excluded from this table.

Abbreviation: PD, Parkinson's disease.

for longer than 1 year. ${ }^{10,13}$ One difficulty associated with assessment of outcomes in long-term studies is accounting for the natural history of PD. As the disease progresses, patient UPDRS scores will worsen regardless of the care they receive. ${ }^{13}$

\section{Difficulties related to technology}

Telemedicine is a way to bring advanced clinical resources and expertise to patients who would not otherwise have access to specialized care. One of the early barriers to effective virtual visits was the technology of the time. Real-time video conferencing has improved dramatically over the past two decades since work in this field began, but there is continued difficulty in reaching patients who either do not have high-speed internet access or do not live near one of the nursing homes or other remote centers established for telemedicine visits.

Patients who lack access to high-speed internet with adequate bandwidth are unable to access services at home. ${ }^{57}$ Furthermore, people with chronic conditions are less likely to have internet access: $72 \%$ of patients with chronic conditions, as compared with $89 \%$ of individuals without chronic conditions, have internet access. ${ }^{58}$ Patients living in urban areas are more likely to have access to academic medical centers at which they could seek specialist care. Telemedicine should be able to increase the availability of specialty care in rural areas, but current research suggests that the number of patients using telemedicine in rural areas is still low. ${ }^{59}$

Earlier studies performed at medical centers found that videoconferencing technology was adequate for detection of gross motor dysfunction, but did not allow for accurate assessment of handwriting, ${ }^{60}$ fine tremor, facial features, less obvious dyskinesia, or limb bradykinesia. ${ }^{8}$ Russell et $a l^{61}$ found that differences between in-person and virtual assessment of balance could have been caused by the remote 
clinicians' inability to determine if patients truly had their eyes closed during a single leg stance test.

While most patients receiving care from home were satisfied with their experiences, others felt that the technological difficulties encountered took away from the value of the interaction. Some regarded the visits as impersonal; one patient specifically mentioned that it was difficult not to talk over one another due to video lag. These concerns about video quality were echoed by a neurologist from the same study, commenting that "fast movements blur." 44 Other patients were concerned when key aspects of the physical exam were missing from home visits, including measuring vital signs ${ }^{43}$ and testing for rigidity and balance. ${ }^{44}$

It has been suggested that assessment of symptom severity varies depending on whether patients are evaluated at home, remotely, or in the office. ${ }^{62}$ It remains unclear whether the home assessment is more accurate because it reflects a patient's natural environment, or if an office assessment is more accurate because clinicians can see the patients more clearly.

\section{Lack of reimbursement}

The complexities of reimbursement for telemedicine visits remain a major barrier for the widespread adoption of the technology. In settings where reimbursement is not an issue (Canada, ${ }^{63}$ the US Department of Veterans Affairs system, ${ }^{64}$ and prison, ${ }^{65}$ ) telemedicine is thriving. The situation is slowly improving, but insurance companies in varying US states differ in their requirements and levels of reimbursement for telemedicine visits. Medicare will reimburse telemedicine visits only in underserved areas and may require that a patient be seen in-person before paying for follow-up telemedicine visits.

Each year, the American Telemedicine Association creates a report of policy updates for the United States, assigning a grade to each state based on their coverage of telemedicine. The most recent report released in February 2017 showed improvement over previous years, as no US state currently has a failing grade. Thirty-one states have parity laws in place to require that health insurance plans reimburse for telemedicine at an equivalent rate as paid for in-person services. This number has doubled over the past 5 years. However, 20 states either have no parity laws in place or have significant barriers to reimbursement. For state employee health plans, half of the country has little to no coverage for telemedicine. ${ }^{66}$

Medicaid programs in all 50 states currently have some form of coverage for telemedicine, but each state has different restrictions. State Medicaid programs determine reimbursement based on patient setting, synchronous vs asynchronous telemedicine technology, the services provided, and informed consent requirements. ${ }^{66}$

Until widespread reimbursement for telemedicine is a reality, most telemedicine services are either cash-paid or charged to the hospital. Some hospitals are making arrangements with other hospitals, agreeing upon flat fees for telemedicine consults and follow-up visits. Other telemedicine programs are forced to rely on grant funding. ${ }^{5}$ If a hospital is unable to cover the cost of telemedicine visits in the current system, patients may be unwilling or unable to pay out-ofpocket. In a survey of 33 patients, $55 \%$ were unwilling to pay more than $\$ 50$ per month for their telemedicine visits despite the savings and convenience it provided; only $9 \%$ would be willing to pay over $\$ 150$ per month. ${ }^{43}$

\section{Licensing complications}

Current laws in most US states require that physicians be licensed in the state where the patient is physically located, limiting the reach of telemedicine in underserved states. This could potentially prevent the delivery of life-saving care to a patient in one state that would be available to a patient in a neighboring state. Certain states are attempting to improve this problem by allowing physicians to join the Interstate Medical Licensure Compact (IMLC) established by the Federation of State Medical Boards. The IMLC was designed to create a streamlined process by which physicians could become licensed in multiple states. Twenty-two states belong to the IMLC at the time of this publication, but member states vary in their level of implementation. ${ }^{67}$ At the current time, no state in the US earned a grade of " $\mathrm{A}$ " in the Licensure and Out-of-State Practice category in the annual report released by the American Telemedicine Association. ${ }^{68}$

\section{Ideal practice design}

On the basis of the strengths and weaknesses of telemedicine we have outlined, it is possible to describe some of the qualities of an ideal telemedicine program. Many of the technological difficulties reported in the literature were due to variability in the technology available to each patient. Difficulties were also encountered in attempting to treat patients from the community at a continuous care facility where they were not current residents. We therefore conclude that a successful telemedicine program will need to be based in a remote clinic with the resources to construct reliable video conferencing. This will ensure consistently adequate communication with a movement disorder specialist. Before a virtual visit is scheduled, patients would be seen in person to establish a relationship with a movement 
disorder specialist and to give informed consent to receive care via telemedicine.

Both ends of the transmission will need to be equipped with high-definition video recording equipment, as well as a secure network connection with adequate high speed and bandwidth. There are a number of products on the market that are suitable for secure video conferencing. The system with which the authors are most familiar is the TANDBERG Centric 1700 MXP. This system uses Advanced Encryption Standard (AES) when possible with 128 bits encryption; if AES is not supported, Data Encryption Standard (DES) is used with 56 bits encryption. ${ }^{69}$ The TANDBERG Centric 1700 MXP also utilizes H.235 and IEEE 802.1x authentication described by the International Telecommunication Union and the Institute of Electrical and Electronics Engineers, respectively. ${ }^{70,71}$ Videos during virtual visits are live-streamed and do not need to be stored, as the medical chart documentation serves as a record of the encounter. If videos are to be stored, the video files should be kept in a secure storage server with the highest level of encryption.

The treatment room must be large enough to allow patients to walk freely for accurate assessment of gait. It is also imperative that the room be well-lit, allowing the movement disorder specialist to detect fine tremor and facial movements. Patients with PD may be at an increased risk of falling, and as such, the facility should be set up with patient safety in mind.

Once the location is established, faculty and staff to carry out the visits must be identified. The treatment team should include at least one neurologist trained in the treatment of movement disorders. The staff of the remote clinic or continuous care facility will include technical partners, nurses, or nurse practitioners trained to take a medical history and vital signs, assist with hands-on portions of the exam, and calculate a UPDRS score. These team members will be thoroughly trained to ensure that the examination is performed safely, especially while testing gait and balance. If a patient falls during the exam and is injured, responsibility for the event will be determined on a case by case basis. Remote clinic staff can also assist in reconciling medications, making sure that patients are receiving their medications via electronic prescription sent directly to their pharmacy.

A practice manager is valuable not only in managing patient visit schedules along with the schedules of each individual staff member, but also in helping to integrate the telemedicine schedule with the physician's schedule for inperson visits. A staff member well-versed in billing practices for telemedicine can be utilized to avoid confusion regarding the complexities of reimbursement. Technology support personnel should be present or readily available both for system setup and troubleshooting problems related to the video conferencing equipment and network connectivity.

This remote clinic may serve as a multi-disciplinary PD treatment center, in which physical therapists, occupational therapists, clinical psychologists, speech and language pathologists, and other specialty practitioners can operate to streamline care for patients. Ideally, this remote clinic will work with community outreach organizations and social workers to recruit and coordinate telemedicine care for underserved patients.

\section{Conclusions and future development}

If current projections are accurate, the global population of patients with PD will double from the years 2005-2030. ${ }^{72}$ Telemedicine has the potential to become a critical piece of the delivery of care to this growing number of patients. As technology advances over time, the cost of equipment required to provide telemedicine to patients will decrease, allowing facilities to purchase the equipment more readily. ${ }^{10}$ Patients are becoming more comfortable with video conference technology and the number of elderly people with access to the internet is increasing. ${ }^{73,74}$

The current research on telemedicine for the delivery of care to patients with PD has laid an effective groundwork, but there are areas yet unexplored. Future research will need to include larger patient samples including patients from diverse ethnic backgrounds, individuals with lower levels of education and income, and patients with more severe levels of disability before a thorough assessment of telemedicine can be made. Research will also need to be conducted to more thoroughly understand how smartphones and emerging technologies can be used for remote monitoring and treatment.

A newer version of the UPDRS, called the MDS-UPDRS was published in 2007 by the Movement Disorder Society. This scale was created to give more attention to the non-motor features of PD, as well as to address the lack of consistent anchoring between subscales on the original UPDRS. Since its publication, the MDS-UPDRS has been shown to have high internal consistency, correlation with the UPDRS, and validity for rating PD. ${ }^{75}$ Future research may rely upon this new scale to capture the ways in which telemedicine can be used to address the non-motor symptoms of PD, giving a more comprehensive picture of its applications.

Another classification instrument that may become integrated into the care of PD is the International Classification 
of Functioning, Disability, and Health (ICF). The ICF was developed as a scientific tool to characterize the structure and functioning of an individual, the ability to carry out tasks, and the environmental and social factors that contribute to overall health. There is a strong correlation between the motor and non-motor manifestations of PD with the domains of the ICF, but only a few studies have specifically studied this connection. $^{76-80}$

Emerging treatment modalities will inevitably affect the applications of telemedicine for patients with PD. New treatments of PD have been focused on reducing the variability in symptoms that patients with PD experience through the administration of several doses of oral medications throughout the day. Among the newer treatment modalities available to patients with PD is an extended-release carbidopa/ levodopa pump that delivers the medication continuously throughout the day through a percutaneous endoscopic transgastric jejunostomy. This portable delivery system, approved by the FDA in early 2015, may address the increasing amount of "off" time - due to disease progression - that patients experience between doses of oral medications. The system was designed to have the medication bypass the stomach, as gastric emptying can become unpredictable in later PD. ${ }^{81}$

Deep brain stimulation (DBS) is also being used to treat patients whose symptoms cannot be adequately controlled with oral medications. This technology delivers continuous impulses to specific areas of the basal ganglia that affect movement. The future of DBS may include devices that respond to a patient's unique brain signals, delivering impulses only when needed and only to specific cells rather than to a specific area. A recent meta-analysis suggests that targeting the pedunculopontine nucleus specifically may improve postural instability and gait disorder, symptoms that have traditionally remained largely unimproved by DBS treatment. ${ }^{82}$ Although it is safe to perform virtual follow-up visits for patients treated with extended release medication pumps or DBS, adjustments to continuous delivery systems need to be done in person to ensure patient safety. It will still be some time before these technologies can be safely adjusted at a distance without the need for in-person assessments.

In 1992, Dr Jean P. Hubble, ${ }^{83}$ a neurologist at the Kansas University Medical Center, concluded that, "It must be conceded that compressed video transmission will not serve as a substitute for the traditional 'hands-on' clinical interview and examination." While Dr Hubble's statement still rings true more than 25 years later, we are closer than ever to making virtual visit assessment as good as in-person examination with wider access to care, increased convenience for patients, and seamless communication between members of the treatment team.

\section{Acknowledgments}

The authors thank Nicole E. Purcell, DO, for her contributions to "Lack of Reimbursement and Licensing Complications" sections, and Jacqueline Grove for manuscript editing and formatting.

\section{Disclosure}

The authors report no conflicts of interest in this work.

\section{References}

1. Hirsch L, Jette N, Frolkis A, Steeves T, Pringsheim T. The incidence of Parkinson's disease: a systematic review and meta-analysis. Neuroepidemiology. 2016;46(4):292-300.

2. Postuma RB, Berg D, Stern M, et al. MDS clinical diagnostic criteria for Parkinson's disease. Mov Disord. 2015;30(12):1591-1601.

3. Jain S. Multi-organ autonomic dysfunction in Parkinson disease. Parkinsonism Relat Disord. 2011;17(2):77-83.

4. Reijnders JS, Ehrt U, Weber WE, Aarsland D, Leentjens AF. A systematic review of prevalence studies of depression in Parkinson's disease. Mov Disord. 2008;23(2):183-189.

5. Pretzer-Aboff I, Prettyman A. Implementation of an integrative holistic healthcare model for people living with Parkinson's disease. Gerontologist. 2015;55(Suppl. 1):S146-S153.

6. Willis AW, Schootman M, Tran R, et al. Neurologist-associated reduction in PD-related hospitalizations and health care expenditures. Neurology. 2012;79(17):1774-1780.

7. Ganapathy K. Distribution of neurologists and neurosurgeons in India and its relevance to the adoption of telemedicine. Neurol India. 2015;63(2):142-154.

8. Dorsey ER, Venkataraman V, Grana MJ, et al. Randomized controlled clinical trial of "virtual house calls" for Parkinson disease. JAMA Neurol. 2013;70(5):565-570.

9. Beck CA, Beran DB, Biglan KM, et al and Connect.Parkinson Investigators. National randomized controlled trial of virtual house calls for Parkinson disease. Neurology. 2017;89(11):1152-1161.

10. Samii A, Ryan-Dykes P, Tsukuda RA, Zink C, Franks R, Nichol WP. Telemedicine for delivery of health care in Parkinson's disease. J Telemed Telecare. 2006;12(1):16-18.

11. Qiang JK, Marras C. Telemedicine in Parkinson's disease: A patient perspective at a tertiary care centre. Parkinsonism Relat Disord. 2015;21(5):525-528.

12. Wilkinson JR, Spindler M, Wood SM, et al. High patient satisfaction with telehealth in Parkinson disease: A randomized controlled study. Neurol Clin Pract. 2016;6(3):241-251.

13. Barbour PJ, Arroyo J, High S, Fichera LB, Staska-Pier MM, McMahon MK. Telehealth for patients with Parkinson's disease: delivering efficient and sustainable long-term care. Hosp Pract. 20162016;44(2):92-97.

14. Barroso Júnior MC, Esteves GP, Nunes TP, Silva LM, Faria AC, Melo PL. A telemedicine instrument for remote evaluation of tremor: design and initial applications in fatigue and patients with Parkinson's disease. Biomed Eng Online. 2011;10:14.

15. Mandal I, Sairam N. Accurate telemonitoring of Parkinson's disease diagnosis using robust inference system. Int J Med Inform. 2013;82(5):359-377.

16. Cancela J, Pastorino M, Arredondo MT, Hurtado O. A telehealth system for Parkinson's disease remote monitoring. The PERFORM approach. Conf Proc IEEE Eng Med Biol Soc. 2013;2013:7492-7495. 
17. Tzallas AT, Tsipouras MG, Rigas G, et al. PERFORM: a system for monitoring, assessment and management of patients with Parkinson's disease. Sensors. 2014;14(11):21329-21357.

18. Cancela J, Fico G, Arredondo Waldmeyer MT. Using the Analytic Hierarchy Process (AHP) to understand the most important factors to design and evaluate a telehealth system for Parkinson's disease. BMC Med Inform Decis Mak. 2015;15(Suppl. 3):S7.

19. Menezes Borges D, Cunha JP. Telemedicine multimedia system to support neurodegenerative diseases participatory management. Conf Proc IEEE Eng Med Biol Soc. 2015;2015:4982-4985.

20. Cancela J, Villanueva Mascato S, Gatsios D, et al. Monitoring of motor and non-motor symptoms of Parkinson's disease through a mHealth platform. Conf Proc IEEE Eng Med Biol Soc. 2016;2016:663-666.

21. Arora S, Venkataraman V, Zhan A, et al. Detecting and monitoring the symptoms of Parkinson's disease using smartphones: A pilot study. Parkinsonism Relat Disord. 2015;21(6):650-653.

22. Kostikis N, Hristu-Varsakelis D, Arnaoutoglou M, Kotsavasiloglou C. Smartphone-based evaluation of Parkinsonian hand tremor: quantitative measurements vs clinical assessment scores. Conf Proc IEEE Eng Med Biol Soc. 2014;2014:906-909.

23. Kostikis N, Hristu-Varsakelis D, Arnaoutoglou M, Kotsavasiloglou C. A smartphone-based tool for assessing Parkinsonian hand tremor. IEEE J Biomed Health Inform. 2015;19(6):1835-1842.

24. Lee W, Evans A, Williams DR. Validation of a smartphone application measuring motor function in Parkinson's disease. J Parkinsons Dis. 2016;6(2):371-382.

25. Lee CY, Kang SJ, Hong SK, Ma HI, Lee U, Kim YJ. A validation study of a smartphone-based finger tapping application for quantitative assessment of bradykinesia in Parkinson's disease. PLoS One. 2016;11(7):e0158852.

26. Pan D, Dhall R, Lieberman A, Petitti DB. A mobile cloud-based Parkinson's disease assessment system for home-based monitoring. JMIR Mhealth Uhealth. 2015;3(1):e29.

27. Kim H, Lee HJ, Lee W, et al. Unconstrained detection of freezing of Gait in Parkinson's disease patients using smartphone. Conf Proc IEEE Eng Med Biol Soc. 2015;2015:3751-3754.

28. Capecci M, Pepa L, Verdini F, Ceravolo MG. A smartphone-based architecture to detect and quantify freezing of gait in Parkinson's disease. Gait Posture. 2016;50:28-33.

29. Ellis RJ, Ng YS, Zhu S, et al. A validated smartphone-based assessment of gait and gait variability in Parkinson's disease. PLoS One. 2015;10(10):e0141694.

30. Ivkovic V, Fisher S, Paloski WH. Smartphone-based tactile cueing improves motor performance in Parkinson's disease. Parkinsonism Relat Disord. 2016;22:42-47.

31. Ginis P, Nieuwboer A, Dorfman M, et al. Feasibility and effects of home-based smartphone-delivered automated feedback training for gait in people with Parkinson's disease: A pilot randomized controlled trial. Parkinsonism Relat Disord. 2016;22:28-34.

32. Liddle J, Ireland D, McBride SJ, et al. Measuring the lifespace of people with Parkinson's disease using smartphones: proof of principle. JMIR Mhealth Uhealth. 2014;2(1):e13.

33. Patel S, Chen BR, Buckley T, et al. Home monitoring of patients with Parkinson's disease via wearable technology and a web-based application. Conf Proc IEEE Eng Med Biol Soc. 2010;2010:4411-4414.

34. Mera TO, Burack MA, Giuffrida JP. Quantitative assessment of levodopa-induced dyskinesia using automated motion sensing technology. Conf Proc IEEE Eng Med Biol Soc. 2012;2012:154-157.

35. Mera TO, Burack MA, Giuffrida JP. Objective motion sensor assessment highly correlated with scores of global levodopa-induced dyskinesia in Parkinson's disease. J Parkinsons Dis. 2013;3(3):399-407.

36. Mancini M, El-Gohary M, Pearson S, et al. Continuous monitoring of turning in Parkinson's disease: Rehabilitation potential. NeuroRehabilitation. 2015;37(1):3-10.

37. Heldman DA, Filipkowski DE, Riley DE, et al. Automated motion sensor quantification of gait and lower extremity bradykinesia. Conf Proc IEEE Eng Med Biol Soc. 2012;2012:1956-1959.
38. Heldman DA, Espay AJ, Lewitt PA, Giuffrida JP. Clinician versus machine: reliability and responsiveness of motor endpoints in Parkinson's disease. Parkinsonism Relat Disord. 2014;20(6):590-595.

39. Piro NE, Piro LK, Kassubek J, Blechschmidt-Trapp RA. Analysis and visualization of 3D motion data for UPDRS rating of patients with Parkinson's disease. Sensors. 2016;16(6):930.

40. Heldman DA, Giuffrida JP, Cubo E. Wearable sensors for advanced therapy referral in Parkinson's disease. J Parkinsons Dis. 2016;6(3):631-638.

41. Ferreira JJ, Godinho C, Santos AT, et al. Quantitative home-based assessment of Parkinson's symptoms: the SENSE-PARK feasibility and usability study. BMC Neurol. 2015;15:89.

42. Dorsey ER, Deuel LM, Voss TS, et al. Increasing access to specialty care: a pilot, randomized controlled trial of telemedicine for Parkinson's disease. Mov Disord. 2010;25(11):1652-1659.

43. Venkataraman V, Donohue SJ, Biglan KM, Wicks P, Dorsey ER. Virtual visits for Parkinson disease: A case series. Neurol Clin Pract. 2014;4(2):146-152.

44. Dorsey ER, Wagner JD, Bull MT, et al. Feasibility of virtual research visits in Fox Trial Finder. J Parkinsons Dis. 2015;5(3):505-515.

45. Shprecher D, Noyes K, Biglan K, et al. Willingness of Parkinson's disease patients to participate in research using internet-based technology. Telemed J E Health. 2012;18(9):684-687.

46. Marzinzik F, Wahl M, Doletschek CM, Jugel C, Rewitzer C, Klostermann F. Evaluation of a telemedical care programme for patients with Parkinson's disease. J Telemed Telecare. 2012;18(6):322-327.

47. Biglan KM, Voss TS, Deuel LM, et al. Telemedicine for the care of nursing home residents with Parkinson's disease. Mov Disord. 2009;24(7):1073-1076.

48. Dorsey ER, Achey MA, Beck CA, et al. National randomized controlled trial of virtual house calls for people with Parkinson's disease: interest and barriers. Telemed J E Health. 2016;22(7):590-598.

49. Dalrymple-Alford JC, Macaskill MR, Nakas CT, et al. The MoCA: wellsuited screen for cognitive impairment in Parkinson disease. Neurology. 2010;75(19):1717-1725.

50. Hatzakis M, Haselkorn J, Williams R, Turner A, Nichol P. Telemedicine and the delivery of health services to veterans with multiple sclerosis. J Rehabil Res Dev. 2003;40(3):265-282.

51. Movement Disorder Society Task Force on Rating Scales for Parkinson's Disease. The Unified Parkinson's Disease Rating Scale (UPDRS): status and recommendations. Mov Disord. 2003;18(7):738-750.

52. Goetz CG, Poewe W, Rascol O, et al. Movement Disorder Society Task Force report on the Hoehn and Yahr staging scale: status and recommendations. Mov Disord. 2004;19(9):1020-1028.

53. Biundo R, Weis L, Bostantjopoulou S, et al. MMSE and MoCA in Parkinson's disease and dementia with Lewy bodies: a multicenter 1-year follow-up study. J Neural Transm. 2016;123(4):431-438.

54. Hubble JP, Pahwa R, Michalek DK, Thomas C, Koller WC. Interactive video conferencing: a means of providing interim care to Parkinson's disease patients. Mov Disord. 1993;8(3):380-382.

55. Abdolahi A, Scoglio N, Killoran A, Dorsey ER, Biglan KM. Potential reliability and validity of a modified version of the Unified Parkinson's Disease Rating Scale that could be administered remotely. Parkinsonism Relat Disord. 2013;19(2):218-221.

56. Dahodwala N, Xie M, Noll E, Siderowf A, Mandell DS. Treatment disparities in Parkinson's disease. Ann Neurol. 2009;66(2):142-145.

57. Hart J. Teleneurology: beyond stroke care. Telemed J E Health. 2010;16(7):772-775.

58. Fox S, Duggan M. The diagnosis difference [webpage on the internet. Pew Research Center. 2013. Available from: http://www.pewinternet org/2013/11/26/the-diagnosis-difference/. Accessed January 4, 2018.

59. Mehrotra A, Jena AB, Busch AB, Souza J, Uscher-Pines L, Landon BE. Utilization of telemedicine among rural Medicare beneficiaries. JAMA. 2016;315(18):2015-2016.

60. Hoffmann T, Russell T, Thompson L, Vincent A, Nelson M. Using the Internet to assess activities of daily living and hand function in people with Parkinson's disease. NeuroRehabilitation. 2008;23(3): 253-261. 
61. Russell TG, Hoffmann TC, Nelson M, Thompson L, Vincent A. Internetbased physical assessment of people with Parkinson disease is accurate and reliable: a pilot study. $J$ Rehabil Res Dev. 2013;50(5):643-650.

62. Cubo E, Gabriel-Galán JM, Martínez JS, et al. Comparison of officebased versus home Web-based clinical assessments for Parkinson's disease. Mov Disord. 2012;27(2):308-311.

63. Brown EM. The Ontario Telemedicine Network: a case report. Telemed J E Health. 2013;19(5):373-376.

64. Darkins A, Ryan P, Kobb R, et al. Care Coordination/Home Telehealth: the systematic implementation of health informatics, home telehealth, and disease management to support the care of veteran patients with chronic conditions. Telemed J E Health. 2008;14(10):1118-1126.

65. Glaser M, Winchell T, Plant P, et al. Provider satisfaction and patient outcomes associated with a statewide prison telemedicine program in Louisiana. Telemed J E Health. 2010;16(4):472-479.

66. Thomas L, Capistrant G. State Telemedicine Gaps Analysis: Coverage and Reimbursement [webpage on the Internet]. American Telemedicine Association. 2017. Available from: https://www.americantelemed.org/ policy-page/state-telemedicine-gaps-reports\#. Accessed February 4, 2018.

67. Interstate Medical Licensure Compact: A faster pathway to medical licensure [webpage on the Internet]; 2018. Available from: http://www. licenseportability.org. Accessed February 4, 2018.

68. Thomas L, Capistrant G. State Telemedicine Gaps Analysis: Physician Practice Standards \& Licensure [webpage on the Internet]. American Telemedicine Association; 2017. Available from: https://www.americantelemed.org/policy-page/state-telemedicine-gaps-reports\#. Accessed February 4, 2018.

69. Centric T. MXP User Manual. Software version F5. D13954.01. 2006. Available from: https://www.vcwarehouse.com/v/vspfiles/ Data_Sheets/tandberg_1700_mxp/videoconferencing-tandberg-centric1700-mxp-user-manual.pdf. Accessed June 27, 2018.

70. International Telecommunication Union (ITU). Baseline security profile. Series H: Audiovisual and multimedia systems. infrastructure of audiovisual services - systems aspects. Telecommunication Standardization Sector of ITU. 2005. Available from: https://www.itu.int/ rec/T-REC-H.235.1-200509-I/en. Accessed June 27, 2018.

71. IEEE standard for local and metropolitan area networks - port-based network access control. IEEE Std 802.1X-2010 (Revision of IEEE Std 802.1X-2004). Available from: http://ieeexplore.iee.org/stamp/stamp. jsp?tp=\&arnumber $=5409813$ \&isnumber $=5409812$. Accessed June 27, 2018.
72. Dorsey ER, Constantinescu R, Thompson JP, et al. Projected number of people with Parkinson disease in the most populous nations, 2005 through 2030. Neurology. 2007;68(5):384-386.

73. Pew Research Center. Internet/broadband fact sheet. Available from: http://www.pewinternet.org/fact-sheet/internet-broadband. Accessed January 4, 2018.

74. Larner A. Telemedicine and older neurology outpatients: use of NHS Direct and of the Internet in the UK. Can Geriatr J. 2011;14(4):104-107.

75. Goetz CG, Tilley BC, Shaftman SR, et al. Movement Disorder Societysponsored revision of the Unified Parkinson's Disease Rating Scale (MDS-UPDRS): scale presentation and clinimetric testing results. Mov Disord. 2008;23(15):2129-2170.

76. Vojciechowski AS, Zotz TGG, Loureiro APC, Israel VL. The international classification of functioning, disability and health as applied to Parkinson's disease: a literature review. Adv Parkinson's Dis. 2016;05(02):29-40.

77. Wynia K, Middel B, van Dijk JP, et al. Broadening the scope on health problems among the chronically neurologically ill with the International Classification of Functioning (ICF). Disabil Rehabil. 2006;28(23):1445-1454.

78. Leonardi M, Meucci P, Ajovalasit D, et al. ICF in neurology: functioning and disability in patients with migraine, myasthenia gravis and Parkinson's disease. Disabil Rehabil. 2009;31(Suppl. 1):S88-S99.

79. Raggi A, Leonardi M, Ajovalasit D, et al. Functioning and disability in Parkinson's disease. Disabil Rehabil. 2010;32(Suppl. 1):S33-S41.

80. Raggi A, Leonardi M, Ajovalasit D, et al. Disability and profiles of functioning of patients with Parkinson's disease described with ICF classification. Int J Rehabil Res. 2011;34(2):141-150.

81. AbbVie. AbbVie announces U.S. FDA approval of DUOPA ${ }^{\mathrm{TM}}$ (carbidopa and levodopa) enteral suspension for the treatment of motor fluctuations in patients with advanced Parkinson's disease. PR Newswire. Available from: http:www.prnewswire.com/news-releases/ abbvie-announces-us-fda-approval-of-duopa-carbidopa-and-levodopaenteral-suspension-for-the-treatment-of-motor-fluctuations-in-patientswith-advanced-parkinsons-disease-300018802.html. Accessed March 28, 2018.

82. Wang JW, Zhang YQ, Zhang XH, Wang YP, Li JP, Li YJ, Jp L, Yj L. Deep brain stimulation of pedunculopontine nucleus for postural instability and gait disorder after Parkinson disease: a meta-analysis of individual patient data. World Neurosurg. 2017;102:72-78.

83. Hubble JP. Interactive video conferencing and Parkinson's disease. Kans Med. 1992;93(12):351-352.
Smart Homecare Technology and TeleHealth

\section{Publish your work in this journal}

Smart Homecare Technology and TeleHealth is an international, peer-reviewed, open access online journal publishing original research, reviews, editorials and commentaries on the application of technology to support people and patients at home and in assisted living centers to optimize healthcare and management resources. Specific topics in the journal include: Development and application of

\section{Dovepress}

devices within the home and embedded in appliances; Healthcare provider communication and education tools; and drug ordering and adherence. The manuscript management system is completely online and includes a very quick and fair peer-review system, which is all easy to use. Visit http://www.dovepress.com testimonials.php to read real quotes from published authors. 